\title{
CONHECIMENTOS, ATITUDES E PRÁTICAS SOBRE SEXUALIDADE ENTRE UNIVERSITÁRIAS: UMA ANÁLISE DA NEGOCIAÇÃO DO USO DO PRESERVATIVO
}

\author{
Maísa Gonçalves Lima ${ }^{1}$, Adriele Cristine de Freitas Batista ${ }^{1}$, Raul Aragão Martins ${ }^{2}$, Janaine Braga \\ Ramos $^{1}$, Luciana Ap. Nogueira da Cruz ${ }^{2}$ \\ ${ }^{1}$ Universidade Estadual Paulista - UNESP, Curso de Pedagogia. ${ }^{2}$ Programa de Pós-Graduação Ensino e Processos \\ Formativos, São José do Rio Preto, SP. E-mail: maisag.lima@hotmail.com \\ Agência de fomento: PIBIC/CNPq
}

\section{RESUMO}

Atualmente no Brasil, aproximadamente 36,7 milhões de pessoas convivem com o HIV/AIDS. O perfil dos infectados por esse vírus vem mudando com o decorrer dos anos, assim como a forma de abordar o tema. O objetivo desse estudo foi compreender como as jovens universitárias conduzem sua sexualidade e negociam o uso do preservativo com seus parceiros eventuais e fixos. A partir dos dados coletados de entrevistas semiestruturadas realizadas com dezoito universitárias, os resultados obtidos apontaram que o uso não regular do preservativo relacionase com fatores relativos à crenças populares e hierarquias de gênero, assim como é influenciado pela educação sexual. Concluiu-se que o distanciamento das práticas protetivas pelas universitárias é uma consequência histórica, que somente poderá ser revertida com o desenvolvimento de uma educação sexual voltada para a responsabilidade e autonomia, tratando a sexualidade como parte integrante do ser humano e não como ato para mera reprodução.

Palavras-chave: Sexualidade, universitárias, prevenção, gênero, negociação.

\section{KNOWLEDGE, ATTITUDES AND PRACTICES ABOUT SEXUALITY AMONG FEMALE COLLEGE STUDENTS: AN ANALYSIS OF THE NEGOTIATION OF CONDOM USE}

\begin{abstract}
Currently in Brazil, approximately 36.7 million people living with HIV / AIDS. The profile of those infected with this virus has changed with the years, as well as how to address the issue. The aim of this study was to understand how the female college students conduct their sexuality and negotiate condom use with their casual and steady partners. From the data collected from semistructured interviews with eighteen universities, the results showed that not regular condom use relates to factors related to popular beliefs and gender hierarchies, and is influenced by sex education. It was concluded that the detachment of protective by the students practices is a historical result, which can only be reversed with the development of a focused sexual education for responsibility and autonomy, treating sexuality as an integral part of the human being and not as an act for mere reproduction.
\end{abstract}

Keywords: Sexuality, university, prevention, gender, negotiation. 


\section{INTRODUÇÃO}

A partir da década de 80 o tema sexualidade ganhou visibilidade por conta da epidemia do HIV/AIDS, atualmente convivem com esse vírus aproximadamente 36,7 milhões de pessoas no mundo e no Brasil 830 mil pessoas estão infectadas (UNAIDS, 2016). Um grupo que merece atenção ao analisar esses dados é o dos jovens universitários, pois, os números apresentados por Geluda et al (2006) apontam que cerca de um terço da população mundial que convive com AIDS possui entre 15 e 24 anos. Este último dado continua sendo uma preocupação, pois no último Boletim Epidemiológico Aids e DST consta que "[...] o fato de que o crescimento de Aids na juventude (15 a 24 anos) continua sendo uma preocupação importante e que as ações nesse segmento tem de ser intensificadas." (MINISTÉRIO DA SAÚDE, 2015, p.3).

Retomando a historicidade das campanhas preventivas, percebemos que essas nem sempre realizadas com a perspectiva atual, a princípio o foco dos trabalhos preventivos eram os indivíduos considerados parte dos "grupos de risco", como gays e usuários de drogas injetáveis, entretanto nos anos 90, o número de casos notificados entre as mulheres, em que a transmissão ocorreu via relações heterossexuais gerou um movimento denominado de "feminização" da epidemia (BRITO; CASTILHO; SZWARCWALD, 2000; GIR et al., 2004). Atualmente considera-se o conceito de vulnerabilidade social, como um esforço de produção e difusão de conhecimento e ações sobre o grau de suscetibilidade do indivíduo à infecção, pressupondo as particularidades formadas pelo conjunto dos aspectos sociais, programáticos e individuais (AYRES, 1997).

Essa mudança conceitual alterou o foco das campanhas preventivas e consequentemente significou um avanço rumo à diminuição da estigmatização criada em torno dos homossexuais e demais grupos tidos como de risco. A nova tarefa de convencer a população em geral de que qualquer pessoa está sujeita a infecção é complexa, pois cada segmento social tem as suas características econômicas, sociais e culturais e grande parte das campanhas preventivas não são elaboradas considerando essas especificidades.

Além dos condicionantes sociais, Silva e Vargens (2008), apresentam em pesquisa feita com mulheres HIV positivas, que a recusa do homem ao uso do preservativo constitui-se como um agravante, essa atitude masculina frente ao sexo seguro pode estar relacionada a dois principais fatores que se interligam: o primeiro diz respeito às crenças populares sobre o uso do preservativo, que como aponta Gir, Duarte e Carvalho (1997), são responsáveis por criar justificativas sociais para o uso não regular desse método preventivo, muitas dessas crenças geram a falsa ideia de o uso acarretará diminuição do prazer, causando inclusive, em alguns homens a impotência sexual no momento de colocar o preservativo. O segundo fator está relacionado à relação de poder que geralmente está presente nos namoros, cujo homem e a mulher ocupam lugares diferentes, determinados pelos papéis de gênero. Geluda et al. (2006), apontam que a fidelidade, a estabilidade e a monogamia, dão aos parceiros uma sensação de sexo seguro, que gera a decisão de não usar o preservativo, mesmo em casos que exista o conhecimento da infidelidade do outro. O constrangimento, as relações de poder existentes entre os gêneros, as reações agressivas e as discussões dolorosas, são fatores que dificultam a negociação do preservativo.

Nesse sentido, este estudo se desenvolveu com o objetivo de compreender esse complexo quadro social, em que mesmo nos casos em que demonstram possuir conhecimento sobre as práticas preventivas as jovens encontram dificuldade ao negociar o uso do preservativo, sujeitando-se a situações de risco como forma de manter suas relações.

\section{METODOLOGIA}

Esta pesquisa é de cunho qualitativo, em que foram realizadas entrevistas presenciais semiestruturadas e foi aprovada por Comitê de Ética em Pesquisa (CAAE: 32482014.4.0000.5466), 
desta forma todas as entrevistadas assinaram o Termo de Consentimento Livre e Esclarecido (TCLE).

O estudo foi realizado em um câmpus de uma universidade pública situada em São José do Rio Preto, interior do estado de São Paulo. O câmpus tem curso nas áreas de Humanidades, Ciências Exatas e Ciências Biológicas.

Trabalhou-se com um grupo de dezoito alunas, sendo que nove entrevistas ocorreram de 2014 a 2015 e, outras nove de 2015 a 2016. Inicialmente foi realizado um convite em um grupo de rede social, onde duas alunas apresentaram interesse em participar da pesquisa, as quais indicaram outra participante e assim sucessivamente.

Inicialmente as entrevistas foram gravadas e, posteriormente transcritas. As informações foram agrupadas em onze categorias, com o objetivo de facilitar as análises (BOGDAN e BIKLEN, 1994). A interpretação de algumas dessas categorias possibilitaram o desenvolvimento do presente artigo.

\section{RESULTADOS}

A amostra coletada proporcionou a análise da trajetória sexual das participantes, o que facilita entender sua conduta de negociação e uso do preservativo. Sete participantes estavam em um relacionamento estável (namoro) na época da entrevista, onze estavam solteiras e uma declarou estar "ficando". Percebe-se uma maior irregularidade no uso do preservativo entre as participantes que namoram, isso pode ser justificado por diversos fatores, como a confiança no parceiro e a estabilidade da relação. Identificamos esse aspecto a partir da categoria "confiança", em que essa justifica a anulação do uso do preservativo:

No começo dessa relação a gente ficou um tempo assim, a gente ficou um tempo, então ele sabia que eu podia ficar com outras pessoas ele também e ai nesse período todo a gente usava preservativo, mais ai a gente decidiu que ficaríamos só nós dois, ah e é uma pessoa assim, que ano que vem acho que a gente vai morar junto, já estamos organizando tudo, então é uma coisa assim, enfim, que acho que a gente não vai mais fazer uso mesmo, é um problema eu sei que "né" (risos) enfim, há muitas mulheres que ficam "né", pegam AIDS pelo marido "né", mais é "foda" também "né" (risos) ( $O$, 23 anos, namorando)

Todas as entrevistadas apontaram o não uso do preservativo como uma vontade ou condição imposta pelo homem, cabendo a elas negociarem, a qual foi denominada categoria de "iniciativa para uso/não uso", no entanto, nota-se muitas vezes que não há negociação e sim uma solicitação que depende do consentimento do homem. Quando o relacionamento assume um caráter estável, a tendência é ceder à vontade masculina, frente ao medo do parceiro duvidar de sua fidelidade.

Comprovando a afirmação de que as crenças populares influenciam o não uso regular do preservativo, aparece a categoria "justificativa para uso/não uso"

[...] a gente saia pra conversar, a gente conversava, tinha um papo super legal, mais ai na hora ele queria, eu falei, ah não vai ter jeito (risos), ele até "broxava" na hora de colocar a camisinha [...] $(0,23$ anos, namorando)

Dentre as dezoito entrevistadas, oito apresentaram a categoria "violência" que refere-se a ter sofrido algum tipo de abuso. Notou-se nessa categoria a dificuldade encontrada pelas participantes em reconhecer e definir o que seria um caso de violência, sendo que grande parte 
delas desconsideram as violências psicológicas e os assédios, tendendo a considerar como violência somente os casos físicos, que costumam ser mais explícitos

Acho que não, acho teve uma vez que... recentemente que eu não, a gente tipo se, nos "amassos assim" e eu falei que a gente tava sem camisinha então não ia ter nada, ai o cara foi e, e colocou sabe e ai eu falei "não sai" na hora assim, só essa vez, mas acho que não.(W, 25 anos, solteira)

Das entrevistadas que namoram, apenas uma declarou que também se responsabiliza por portar preservativo nos casos em que ocorre o uso, as demais apontaram que deixam essa responsabilidade para os parceiros, justificando essa conduta pela facilidade que o homem encontra em adquirir o preservativo em relação ao tabu social encontrado pela mulher.

Atentamos também para as questões relativas à categoria denominada como "tomada de consciência", já que diversas vezes as entrevistadas demonstraram saber as formas de infecção de DSTs e admitiram que suas práticas sexuais até o momento poderiam ser classificadas como de risco, visto que mesmo as que fazem uso do preservativo atualmente já tiveram algum tipo de relacionamento fixo ou eventual sem proteção, no entanto logo após essa tomada de consciência era apontada uma justificativa baseada em crenças populares ou em relações de poder presente dentro do relacionamento para tal conduta.

Relacionado à categoria "discussão sobre o uso do preservativo", notamos nos dados a maior facilidade em realizar a negociação do preservativo entre as jovens que mantém relacionamentos eventuais, pois além de a maioria carregar preservativo quando vão ter uma relação sexual - apesar de em alguns casos não realizarem o uso - a grande maioria propõe o sexo protegido para o parceiro eventual, uma vez que não existe nenhum sentimento envolvido que possa gerar conflito. Entre as que namoram atualmente, percebemos a mesma conduta quando mantinham relacionamentos eventuais.

No começo a pessoa tentou me convencer a começar sem usar né, mas ai eu já falei que não que eu não fazia sem, eu falei "eu não faço sem" e ai como ta no início do relacionamento, foi recente até, é... como ta no início, eu acho que eu não fiquei com muito medo de perder a pessoa, porque no outro eu ficava insegura com relação à isso. (J, 22 anos, namorando)

Uma categoria muito importante é a "Educação Sexual". Em treze entrevistas foi apontado que a escola em alguns momentos tratou da questão da sexualidade, mas sempre através de uma abordagem biologizante, tratando a sexualidade como algo imoral, reprimindo e impondo medo

[...] paras meninas assim o argumento dele era: "depois vocês ficam carregando filho a vida inteira e o cara não (risos)", ele também que "ah! Porque ninguém quer usar a camisinha com vocês", "ah! É rapidinho ninguém vai querer usar, é cinco minutos, só que depois você que vai ficar a vida inteira", de novo voltava nisso "né", de que você vai se ferrar no final, convenceu, a mim convenceu (risos) (J, 22 anos, namorando)

Em contraponto ao enfoque priorizado pela escola, percebemos que a educação sexual familiar, quando essa acontece é sempre uma tarefa assumida pela mãe e assume um caráter muito mais acolhedor, que sana dúvidas, mas que também orienta para os aspectos sociais da sexualidade, as relações de poder, a importância de cuidar do corpo. 
A hipótese para esses dados é que a maioria das jovens que se encontram em um relacionamento do tipo namoro, que consequentemente envolve sentimentos, como carinho e confiança, deixam de usar o preservativo e encontram justificativas sociais através de crenças populares para tais condutas. Porém estar em um relacionamento estável não significa se relacionar sexualmente com apenas com um parceiro.

\section{DISCUSSÃO}

Percebemos através dos dados coletados que grande parte das condutas femininas de negociação e uso do preservativo estão diretamente relacionadas aos papéis de gênero construídos socialmente. Segundo Saffioti (1987) o conceito de gênero relaciona-se às construções sociais e culturais - portanto, não naturais - que determinam os comportamentos, vestimenta, linguagem, lugares de atuação, etc, para cada um dos sexos biológicos. Essas determinações são responsáveis por alimentar determinados tabus que acabam dificultando a relação igualitária entre homens e mulheres, podemos perceber isso durante a fala das entrevistadas quando aparece que fazer sexo é uma premissa masculina, que mesmo quando possuem desejo do ato sexual são capazes de controlar-se, enquanto para os homens essa é uma tarefa quase impossível. Esse discurso do homem selvagem, que possui um desejo indomável, que é incapaz de controlar seu desejo diante da carne pecaminosa da mulher, é o mesmo discurso que legitima diariamente a violência sexual contra mulheres.

Através dos resultados é possível observar que o homem assume um papel dominante tanto nas relações eventuais quanto nas relações entre casais fixos, esse fato pode estar relacionado ao controle histórico que homens mantêm de sua própria sexualidade e da sexualidade de sua parceira, esse controle muitas vezes ultrapassa as barreiras sexuais e atinge instancias emocionais, sendo assim, a fim de evitar conflitos, as mulheres são levadas a aceitar a determinações masculinas frente ao medo do fim do relacionamento.

Diante da dificuldade encontrada pela família em tratar do assunto, a escola apresenta-se como uma das principais saídas, no entanto, como afirma Louro (2005), nossa atual organização escolar produz e reproduz a repressão da sexualidade e reforça os papéis de gênero. A perspectiva biologizante da sexualidade é responsável não somente pela deficiência de informação relativa aos métodos preventivos, como pela criação de preconceitos contra aqueles que já contraíram alguma DST, além de não desmistificar a sexualidade, tratando-a como imoral.

\section{CONCLUSÃO}

Notou-se que o distanciamento das práticas protetivas pelas universitárias pode ser encarado como uma consequência histórica, que resulta na resistência em admitir o movimento de "feminização" da AIDS, levando-as a enxergar a epidemia como uma realidade do outro.

Ressaltamos ainda a necessidade de maiores discussões sobre gênero, a fim de ajudar as jovens a perceberem seu papel dentro do relacionamento, mostrando a importância de combater a supremacia masculina frente às decisões relativas ao corpo e à sexualidade feminina.

Consideramos a importância de que a educação sexual deixe de tratar o sexo como mera reprodução biológica, entendendo-o como um ato social que proporciona prazer, mas também pode trazer complicações de saúde ou gravidez não planejada.

Sendo assim, atentamos para a urgência de uma educação sexual para a responsabilidade e autonomia visando um desenvolvimento saudável da sexualidade humana, que incentive os jovens a respeitarem seu corpo e o corpo de seus parceiros, sendo eles eventuais ou não, assim como promover o uso responsável do preservativo, para que assim sejam diminuídos os índices de infecção por DSTs. 


\section{REFERÊNCIAS}

AYRES, José Ricardo C.M. Vulnerabilidade e aids: para uma resposta social à epidemia. Boletim epidemiológico - C.R.T. - DST/AIDS - C.V.E. - Ano XV - № 3 - Dezembro 1997, São Paulo, pp-2-4

BOGDAN, r. c.; BIKLEN, S. K. Investigação qualitativa em educação. Porto, Porto Editora, 1994.

BRITO, Ana Maria de; CASTILHO, Eucilides A. de e SZWARCWALD, Célia L. AIDS e infecção pelo HIV no Brasil: uma epidemia multifacetada. Revista da Sociedade Brasileira de Medicina Tropical. 34(2): 207-17, mar-abr., 2000.

GELUDA K. et al. "Quando um não quer, dois não brigam": um estudo sobre o não uso constante de preservativo masculino por adolescentes do Município do Rio de Janeiro, Brasil. Cad. Saúde Pública, Rio de Janeiro, 22(8):1671-1680, ago, 2006.

GIR, E.; DUARTE, G.; CARVALHO. M.J de. Opinião de universitários sobre o uso do condom e sua influência no exercício da sexualidade. Medicina, Ribeirão Preto, 30: 100-105, jan./mar. 1997.

LOURO, G. L. Gênero, Sexualidade e Educação: uma perspectiva pós-estruturalista. 6a ed.

Petrópolis, RJ: Vozes, 1997.

MINISTÉRIO DA SAÚDE. Boletim Epidemiológico Aids e Dst. Brasília: Ministério da Saúde. Ano IV, $\mathrm{n}^{\circ}$ 1, 2015.

[http://www.aids.gov.br/sites/default/files/anexos/publicacao/2015/58534/boletim_aids_11_201 5_web_pdf_19105.pdf]

SAFFIOTI, H. I. B. O poder do macho. Editora Moderna. São Paulo, SP, 1987.

SILVA, C.M; VARGENS, O.M.C. A percepção de mulheres quanto á vulnerabilidade feminina para contrair DST/HIV. Revista da Escola de Enfermagem da USP, São Paulo -SP, 2009.

UNAIDS Programa Conjunto das Nações Unidas sobre HIV/Aids. [periódico na Internet] Disponível em: http://www.unaids.org/en/dataanalysis/datatools/aidsinfo/. 2016. [Acesso em 7 ago. 16]. 